\title{
Exploration and application of directional long boreholes in coal measure strata
}

\author{
Qin $\mathrm{Ke}^{1}$, Peng Dong ${ }^{1}$, Duan Huijun ${ }^{1,2^{*}}$ \\ ${ }^{1}$ Xi'an Research Institute of China Coal Technology and Engineering Group Corp, Xi'an; China \\ ${ }^{2}$ China Coal Research Institute, Beijing; China
}

\begin{abstract}
Baode Mine may have the risk of water inrush at the same time, so it is necessary to construct long borehole to cover the roadway excavation. On the basis of the hydrogeological conditions of the mine, the safe water insulation thickness and water inrush coefficient of coal seam No .8 are calculated. The results show that the water inrush coefficient is $0.035-0.037 \mathrm{MPa} / \mathrm{m}$, which is less than the critical value $0.06 \mathrm{MPa} / \mathrm{m}$ and the bottom plate has no sudden water hazard. In the construction of No .10 coal seam, the directional long borehole is used to detect whether there is a hidden structure communicating with the floor limestone and to drain water. The test shows that there is no effluent phenomenon in the borehole, which proves that there is no hidden structure in No .10 coal seam.
\end{abstract}

\section{INTRODUCTION}

The directional drilling technology has developed rapidly in recent years because of its controllable drilling track, accurate measurement of drilling track and high target layer drilling rate. At present, it has been widely used in the fields of water exploration, gas prevention and control, floor grouting reconstruction, geological structure exploration and so on ${ }^{[1-5]}$. The construction of fan-shaped multi-branch directional holes in the target horizon can increase the coverage area of the borehole and better explore the geological conditions of the target horizon. ${ }^{\text {[- }}$ ${ }^{10]}$ The rubber roadway of No .8 coal 81312 face and the auxiliary roadway of 81313 face developed by Baode Coal Mine are restricted by the existence of limestone water inrush in the bottom plate, which affects the rapid recovery of mining area. At present, roadway excavation is needed for mining surface, and it is urgent for construction drilling to explore the water rich condition of roadway floor limestone and cover roadway excavation. Therefore, the multi-branch directional drilling is used to solve the problem in the bottom plate No .10 coal, and the drilling construction of water exploration and discharge hole is carried out to ensure the safety of roadway excavation.

\section{HYDROGEOLOGICAL CONDITIONS IN MINING AREAS}

The Baode coal mine is located on the east bank of the Yellow River and on the northwest margin of Shanxi, which belongs to the Loess Plateau. It is characterized by loess gully and hilly landform. The overall terrain is low in the middle and high in the north and south $\mathrm{m}$, with the highest elevation of $1148.1 \mathrm{~m}$, and the lowest in the northern county seat of the mine. The elevation is about $815 \mathrm{~m}$, and the maximum height difference is $335.9 \mathrm{~m}$. The maximum height difference is 335.9 The main water source of the deposit is groundwater, including fissure water of sandstone and Ordovician limestone at the top and bottom of coal seam. The type of water filling is mainly karst water filling, coal system fissure water filling, and indirect water filling. The water level of Ordovician limestone karst water in Baode Mine is +839 m,81312 rubber transportation ,8131313 auxiliary transportation channel $0-700 \mathrm{~m}$ section heading face floor elevation is 544 565 m, located below Ordovician ash water level $274 \sim 295 \mathrm{~m}$, water pressure is $2.74 \sim 2.95$. It belongs to pressure driving.

\section{RISK ANALYSIS OF ORDOVICIAN WATER INRUSH IN BOTTOM PLATE}

The mining of coal seams caused the overlying bedrock to fall and form a new water-conducting fissure zone. However, the basement fractured aquifer of the coalmeasure strata in this area and its overlying third and fourth series loose pore aquifers are recharged by weak water-rich aquifers. The amount is limited, and it forms a complementary relationship with the surface water with the change of topography and valley, which poses little threat to the existing coal seam. With the mining of coal seam, the load reduction effect will be formed on the bottom plate. In case of hidden water conduction structure of coal seam floor, it is an important channel to conduct Ordovician karst water with the characteristics of large recharge, high water head and high water pressure. Water inrush coefficient is a quantitative index to characterize the possibility of mine water inrush. The water inrush coefficient depends on the water pressure on the coal seam

*Corresponding author: duanhuijun@cctegxian.com 
floor $^{[11-12]}$. According to the Code for Geological Exploration of Hydrogeological Engineering in Mining Area (GB12719-1991) and the Rules for Prevention and Control of Water in Coal Mine, the following formula (1) (2) is used to calculate the safe water barrier thickness and water inrush coefficient of coal seam floor in this working face.

$$
\begin{gathered}
t=\frac{L \sqrt{\gamma^{2} L^{2}+8 k_{p} p-\gamma L}}{4 k_{p}} \\
\mathrm{~T}_{\mathrm{s}}=\mathrm{P} / \mathrm{M}
\end{gathered}
$$

When the $\mathrm{P}$ value is $3.91-4.13 \mathrm{MPa}$, the water inrush coefficient of the excavated surface is calculated to be $0.035-0.037 \mathrm{MPa} / \mathrm{m}$, less than the critical value 0.06 . Therefore, the fan-shaped multi-branch directional drilling in No.10 coal is used to detect whether there are hidden structures in the coal seam, so as to judge the possibility of water diversion of the bottom limestone.

\section{DRILLING EQUIPMENT AND CONSTRUCTION TECHNOLOGY}

\subsection{Drilling equipment}

ZDY6000LD high power deep hole directional drilling rig is used in the drilling construction of the cover roadway, Has $6000 \mathrm{~N} \cdot \mathrm{m}$ output torque, High gyration, $250 \mathrm{kN}$, rig feed/drawing capacity Suitable for directional drilling of hole bottom motor, rotary drilling of orifice and compound drilling. Matching BLY390 mud pumps, Hydraulic drive, Can guarantee enough pressure at high displacement, Maximum pump capacity L/min,390 12 $\mathrm{MPa}$, rated pressure It can meet the requirement of directional long drilling. A measurement system using YHD2-1000(A) with drill, It is composed of explosionproof computer, explosion-proof keyboard, explosionproof data memory and probe tube. As the main extension of the drilling is hard limestone formation, the screw drilling tool in the hole uses 4-stage screw motor. Other supporting drilling tools mainly include drill bits, central cable drill pipes and rotary drill pipes. The hole blowout preventer is installed at the orifice, When the drill is out of the hole, the blowout preventer can be held tight, Prevent borehole effluent. The main construction equipment, models and uses are shown in Table 1.

Table 1 Construction equipment

\begin{tabular}{|c|c|}
\hline Name of equipment & Purpose \\
\hline $\begin{array}{c}\text { Crawler full hydraulic pit } \\
\text { rig }\end{array}$ & Provide drilling power \\
\hline Mud pump & Supply flushing fluid \\
\hline $\begin{array}{c}\text { Measuring system with } \\
\text { drill }\end{array}$ & $\begin{array}{c}\text { Measuring borehole } \\
\text { parameters }\end{array}$ \\
\hline Screw drill & $\begin{array}{c}\text { Transmission power, } \\
\text { deflection }\end{array}$ \\
\hline orifice blowout preventer & Prevent borehole outflow \\
\hline Non-magnetic drill pipe & $\begin{array}{c}\text { shielding magnetic field } \\
\text { interference }\end{array}$ \\
\hline Central cable drill pipe & $\begin{array}{c}\text { Flushing fluid channel, } \\
\text { signal transmission medium }\end{array}$ \\
\hline
\end{tabular}

\begin{tabular}{|c|c|}
\hline $\begin{array}{c}\text { Four-wing flat-angle } \\
\text { PDC drill }\end{array}$ & $\begin{array}{c}\text { Construction of directional } \\
\text { inclined hole section }\end{array}$ \\
\hline PDC reaming bit & $\begin{array}{c}\text { Use of construction casing } \\
\text { sections }\end{array}$ \\
\hline
\end{tabular}

\subsection{Construction process}

\subsubsection{Working face profile}

The $0-600$ section of 81312 rubber transport and 81313 auxiliary transport channel is located in the southern part of the mine field, with 81312 design face in the east, auxiliary transport roadway in the deep part of the third (lower) plate area in the north, the remaining section of the roadway in the south and the boundary of the mine field, and the unmined solid coal body in the west. The coal seam excavated in the working face is Permian coal seam, the coal and rock strata are generally near the north-south strike, showing a monoclinic structure inclined to the west, and the coal seam inclination angle is $3^{\circ} \sim 7^{\circ}$, with an average of about $4^{\circ}$. The coal seam thickness tends to be stable basically, the coal seam thickness at the opening is $6.88 \mathrm{~m}$, and the coal thickness is $7.2 \mathrm{~m}$. after entering the ancient river scour zone The structure of coal seam is complex, the gangue is $4 \sim 5$ layers, the lithology is mudstone and sandy mudstone, the maximum thickness of single layer gangue is $1.4 \mathrm{~m}$.

\subsubsection{Design of borehole structure}

The formation conditions of borehole test area are good and the hardness of coal seam is large, which is beneficial to drilling hole. In the process of roadway excavation, the stratum stress is released, and the fissure area with a certain area becomes the channel to communicate the limestone water of the floor. Find out whether there is water inrush danger in the process of roadway excavation, cover roadway excavation. According to the design requirements of directional drilling, combined with the geological conditions of the mining area, the directional drilling structure is designed as follows: first, the $\Phi 120 \mathrm{~mm}$ PDC bit is used to open the hole, then the $\Phi 193 \mathrm{~mm}$ PDC bit is reamed, and finally the steel casing is $\Phi 146 \mathrm{~mm} 50 \mathrm{~m}$ grouting fixed hole. The second open directional section drilling adopts $\Phi 120 \mathrm{~mm}$ PDC bit $+\Phi 89$ mm screw motor $+\Phi 89 \mathrm{~mm}$ without magnetic drill pipe.

\subsubsection{Drilling technology construction plan}

The drilling water exploration range is $630 \mathrm{~m} 、 81312$ in front of the heading head and $20 \mathrm{~m}$ 、 the final hole is located at $10 \#$ In coal. Drilling detection horizontal distance of $630 \mathrm{~m}, 30 \mathrm{~m}$, ahead $600 \mathrm{~m}$. allowable tunneling distance A total of 1 main hole (inclination $-10^{\circ}$ ), 4 branch holes, The boreholes are fan - shaped, Main hole $677 \mathrm{~m}, 1$ branch hole $656 \mathrm{~m}, 2$ branch hole $650 \mathrm{~m}, 3$ branch hole 638 $\mathrm{m}, 4$ branch hole 644The borehole trajectory is linearcurve, $\Phi 159 \mathrm{~mm}$, of diameter of a straight section of a borehole Under the "Coal Mine Water Control Rules ", the 
straight hole section of the casing is drilled into the steel orifice pipe with $15.5 \mathrm{~m}$ long $\Phi 133 \mathrm{~mm}$, Cement slurry is used to seal the pipe. After the cement has solidified for 24 hours, the pressure test of orifice pipe was carried out. The test pressure is 1.5 times the local water pressure and lasts for 30 minutes. The orifice casing is not loose and there is no water leakage around the orifice, indicating that the orifice tube sealing process is qualified. The curvature radius method is used to calculate the trajectory of the borehole in the oblique section of the borehole, The borehole trajectory of the curve oblique section is obtained. After the curve stabilization section successfully enters the target layer, By controlling the tool surface of the drilling tool, the trajectory is approximately extended to the final hole in the target layer by a straight line.

\section{KEY TECHNOLOGIES AND CONSTRUCTION TECHNIQUES}

\subsection{Key technologies}

\subsubsection{Wireline Drilling Measuring Technology}

Coal mine downhole wireline drilling measurement technology is suitable for drilling about $700 \mathrm{~m}$ deep hole. It is economical, reliable, convenient and quick to use wireline drilling in this depth. Using YHD2-1000(A) with drilling measurement system to $\Phi 73 \mathrm{~mm}$ the central cable drill pipe drilling, every $3 \mathrm{~m}$ of drilling process drilling inclination and azimuth data collection, combined with the geological conditions of coal seam and hole slag return, Adjust the tool angle of drilling tool, adjust the appropriate drilling pressure and pump quantity, so that the borehole extends according to the design track.

\subsection{2 main hole opening branch technology}

In order to explore the geological condition of No .10 coal seam more efficiently and accurately, In the construction process, the branch hole should be opened on the basis of the main hole. At present, the main hole branch opening methods commonly used in coal measure strata are, Low speed grinding branch method and repeated grinding branch method ${ }^{[13]}$. A low-speed grinding branch method sets the tool angle to $180^{\circ}$, Mechanical drilling speed to $6 \sim 8 \mathrm{~m} / \mathrm{h}$ slow drilling until new branch hole ${ }^{[14-15]}$. Grinding the drill tool angle to $180^{\circ}$, Mechanical drilling speed to $20 \sim 30 \mathrm{~m} / \mathrm{h}$ faster drilling, When all the drilling tools enter the new hole, After repeated grinding 2 times and can normally add drill pipe to continue drilling, Until a new branch hole is opened ${ }^{[16-17]}$. Average thickness of Baode Coal Mine 10 is only $1.5 \mathrm{~m}$, The target coal seam thin needs to adjust the tool surface angle of the bottom screw drilling tool more accurately through the orifice monitor, Make the borehole track extend in the coal seam. In order to ensure that the borehole trajectory does not exit the coal seam, The single change of borehole inclination and azimuth is controlled at $0.5^{\circ} \sim 0.8^{\circ}$. After the main hole construction is completed, the branch hole construction is carried out by using the "backward" branch opening method, Drill the drill bit back to the branch point reserved for drilling trajectory design, Low speed grinding method, Make the drill bend down, slow down, Until the new hole is drilled to the design branch hole depth, Repeat the process of opening the branch hole before drilling the remaining branch hole.

\subsection{Construction technology}

\subsection{1 face profile}

The working face of 81312 is located in the southern part of the mine field, and the driving roadway of the working face adopts the form of double roadway excavation. The main coal seam is Permian No .8 coal seam, the coal seam is north-south strike, inclined to west, inclined angle is $3^{\circ} \sim 7^{\circ}$, coal thickness $7.2 \mathrm{~m}$, contains $4 \sim 5$ layers of sandy mudstone gangue, the maximum thickness of gangue is $1.4 \mathrm{~m}$.

\subsubsection{Drilling Structure Design}

The hardness of coal seam in drilling exploration area is large, which is beneficial to drilling hole. In the process of roadway excavation, the stratum stress is released, and the fissure area with a certain area becomes the channel to communicate the limestone water of the floor. It is necessary to construct fan-shaped multi-branch directional long borehole to explore the hidden structure of the floor. According to the construction intention of directional drilling, combined with the geological conditions of mining area, the directional drilling structure is designed as follows: first, the $\Phi 120 \mathrm{~mm}$ PDC bit is used to open the hole, then the $\Phi 193 \mathrm{~mm}$ PDC bit is reamed, and finally the steel casing is $\Phi 146 \mathrm{~mm} 50 \mathrm{~m}$ grouting fixed hole. The second open directional section drilling adopts the $\Phi 120 \mathrm{~mm}$ PDC bit $+\Phi 89 \mathrm{~mm}$ the screw motor $+\Phi 89 \mathrm{~mm} \Phi 89 \mathrm{~mm}$ without the magnetic drill pipe.

\subsubsection{Construction Plan of Drilling Technology}

The drilling exploration range is $630 \mathrm{~m}, 81312$ in front of the heading head and $20 \mathrm{~m}$, of the final hole outside the positive side of the 81313 auxiliary transportation channel is located in No .10 coal. $630 \mathrm{~m}$, horizontal distance from borehole survey $30 \mathrm{~m}$, ahead $600 \mathrm{~m}$. allowable tunneling distance A total of 1 main hole (inclination $-10^{\circ}$ ), 4 branch holes, The boreholes are fan - shaped, Main hole $711 \mathrm{~m}, 1$ branch hole $717 \mathrm{~m}, 2$ branch hole $711 \mathrm{~m}, 3$ branch hole $711 \mathrm{~m}, 4$ branch hole 717 The borehole trajectory is linearcurve, $\Phi 159 \mathrm{~mm}$, of diameter of a straight section of a borehole Under the "Coal Mine Water Control Rules ", the straight hole section of the casing is drilled into the steel orifice pipe with $15.5 \mathrm{~m}$ long $\Phi 133 \mathrm{~mm}$, A PO425R type of early strength cement slurry containing a certain amount of expander is used to seal the orifice pipe, Hou Ning 48 h, After Hou Ning finished sweeping the cement plug, And the water injection pressure test, $4.5 \mathrm{MPa}$, water injection pressure Duration $60 \mathrm{~min}$, No hole casing loose, no leakage phenomenon is the hole pipe sealing qualified. 
The curvature radius method is used to calculate the trajectory of the borehole in the oblique section of the borehole, The borehole trajectory of the curve oblique section is obtained. After the curve stabilization section successfully enters the target layer, By controlling the tool surface of the drilling tool, the trajectory is approximately extended to the final hole in the target layer by a straight line. The borehole design trajectory plan is shown in figure 1.

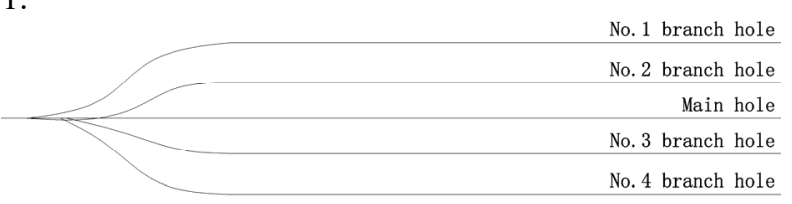

Fig .1 Plane diagram of borehole design trajectory

\section{ANALYSIS OF TEST CONDITIONS AND EFFECT}

As a result of this survey, the expected engineering quantity of the design has been completed, and the total drilling advance is $\mathrm{m} .3567$ In the drilling process, the track is controlled in real time by the wired drilling measurement system. After the construction of the main hole is completed, the construction of the other four branch holes is completed by the "backward" side drilling branch method. Using the fan-shaped multi-branch directional long borehole covering and exploration in the whole area of No .10 coal seam, there is no hole collapse and drilling phenomenon in the construction process, and there is no outlet phenomenon after the final hole of the borehole, which indicates that there is no hidden structure in the bottom plate of No .8 coal seam, and forms a channel to communicate with the high-rise pressure water of the bottom plate. In the later stage, the borehole is used as the gas pre-drainage borehole in No .10 coal seam and the gas interception borehole near No .8 main coal seam. From figure 2, it can be seen that the gas purity increases from unstable to $1.75 \mathrm{~m}$ after drilling and pumping3The min fluctuation is $0.77 \sim 2.35 \mathrm{~m}$ in gas drainage $3 \mathrm{~min}$, average $\mathrm{m} 1.833 \mathrm{~min}$; gas concentration is up to $82.4 \%$, basically above $60 \%$, high concentration gas can meet the requirements of gas power generation.

\section{CONCLUSIONS}

(1) The long-distance water exploration and discharge drilling is used to realize the complete separation between the water exploration and discharge operation and the tunneling operation, which reduces the scope of the cross operation water damage under special circumstances, and improves the working efficiency of the water exploration and discharge operation and the tunneling operation.

(2) A set of fan-shaped multi-branch directional long boreholes were constructed. By adjusting the trajectory of the boreholes in time, full coverage of the detection area was realized, and the precise detection effect was ensured.

\section{REFERENCES}

1. D. Zhang, Q. Li, J. Fang. gas drainage technology and application of one hole and two gas elimination in cluster branch directional drilling group. Safety in Coal Mine. 49,49-53(2018)

2. J. Zhang. Coal mine directional drilling trajectory prediction technology. Safety in Coal Mine. 46,83-86 (2015)

3. N. Yao, J. Zhang, Q. Li. Research and practice of comb directional drilling technology in coal mine. Coal science and Technology,40,30-34 (2012).

4. J. Zhang, N. Yao, Q. Li. Application of directional drilling technology in coal mine geological exploration. Safety in Coal Mine,43 131-134(2013).

5. X. Dou, T. Wei, L. Wang. Application of directional drilling technology in water exploration and drainage of shield roadway in Zhangji coal mine. Safety in Coal Mine,49,179-183(2013).

6. F. Xu, M. Yang. Application of directional drilling technology in water control in Shendong mining area. Mining Safety and Environmental Protection,44,7073(2017).

7. Z. Ji. Application of water exploration and drainage technology in mine hydrogeological supplementary exploration. Coal Geology of China, 26,30-33 (2014).

8. Z. Li. Application of long-distance directional drilling technology in exploration of small coal mine boundary and gob water. Coal Engineering, 47,36-38 (2015).

9. N. Yao, J. Zhang. Research and application of near horizontal directional drilling technology in underground coal mine. Coal science and Technology, 39, 53-57 (2011).

10. X. Sun, Y. Wang, Y. Guo. Application of directional drilling technology in underground water exploration and drainage hole construction in coal mine. Coal Geology and Exploration, 33, 101-103(2004).

11. J. Song, Z. Wang. One hole multi-purpose gas drainage technology in coal mine. Safety in Coal Mine,47,73-76 (2016).

12. F. Jing, F. Li, Y. Wu. Study on Application of one hole multi-purpose technology of surrounding rock extraction drilling in Zhong ma cun mine. China coal,43,155-158 (2017).

13. Z. Wu, Y. Li, X. Wang. Application of multi branch hole technology in grouting treatment of goaf in shallow steep seam. Coal Technology. 38, 136-138 (2019).

14. Y. Li. Research on drilling construction and extraction effect of multi branch through gangue in multi-layer gangue intercalated low permeability thick coal seam in Baode coal mine. Inner Mongolia coal economy, 14, 130-131 (2018).

15. Q. $\mathrm{Wu}, \mathrm{S}$. Zhao, S. Dong. Coal mine prevention and control volume. Beijing: Coal Industry Press, 2013. 
16. P. Ren. Application of directional long drilling in roof water exploration and drainage of Mudu Chaideng coal mine. Exploration Engineering,41, 17-19 (2014).
17. X. Zhao, X. Jin. Technology and application of horizontal directional drilling to detect and draw sandstone water in Coal Seam Roof. Coal Mine Machinery,37,135-137(2016). 